\title{
MONTE CARLO ANALYSIS FOR THE BLAST RESISTANCE DESIGN AND ASSESSMENT OF A REINFORCED CONCRETE WALL
}

\section{Pierluigi Olmati}

\author{
School of Civil and Industrial Engineering, Sapienza University of Rome \\ Via Eudossiana 18 - 00184 Rome (ITALY) \\ e-mail: pierluigi.olmati@uniroma1.it
}

Keywords: Blast Design, Precast Concrete Wall, Fragility Curves, SDOF Method, NonLinear Analysis.

\begin{abstract}
This paper presents a probabilistic approach for the design and assessment of structural elements under blast loads. The procedure is based on the broadly adopted fragility analysis method, widely implemented in Performance-Based Design procedures for structures subjected to natural hazards such as earthquake and wind. A discussion on the uncertainties related to blast engineering problems and on their implementation in a Performance-Based Design approach is presented, followed by an application aiming at the blast protective performance assessment of panels. The non-linear dynamic analyses are carried out by the equivalent non-linear single degree of freedom (SDOF) method. Consequently, the probability failure is computed using both Monte Carlo simulations and fragility curves.
\end{abstract}




\section{INTRODUCTION}

Extreme loads can produce severe consequences on civil structures since these are not designed to have adequate strength to withstand extreme events. Sensible buildings and critical infrastructures are particularly prone to external man-made bomb attacks. The community is nowadays interested in these issues, especially after the escalation of dramatic events in the 1990's, concluding with the September 11 attacks.

The design for hardened structures to withstand blast loads is a common practice for many federal and commercial buildings. Generally in the design practice, a set of attack scenarios is selected and the structural members are verified using non-linear dynamic analyses with the equivalent single degree of freedom (SDOF) method. In such a way (that is adopting a deterministic approach) the failure probability is not evaluated, principally because there is a lack of knowledge of the hazard probability density function. This is common also for LPHC (Low Probability - High Consequence) events [1].

In the design practice adopting a deterministic approach for structural components subjected to blast loads the mechanical properties of the materials are taken equal to appropriate fractile values, and the demand is not probabilistically characterized. In [2] it is suggested to use a multiplicative coefficient of $20 \%$ on the appropriate amount of explosive for the design scenario, but this is limited to a scenario concerning explosive storage facilities. In an antiterrorism design, the amount of explosives used in an attack is generally characterized by an elevated amount of uncertainty.

In recent years, several probabilistic approaches in blast engineering problems have been proposed. In [3] Monte Carlo simulations are performed in order to estimate the failure probability for windows subjected to a blast load from a vehicle bomb. In [4] the fragility curves are presented for two kinds of glazing systems. In this study a similar effort is made focusing on a precast concrete cladding panel.

A cladding system in precast concrete walls has some advantages with respect to traditional masonry claddings (without structural function). In [5] studies are performed for the improvement of traditional masonry cladding. The first advantage of precast concrete panels with respect to the traditional masonry cladding, concerning the blast load considered in this paper, is the greater resistance to this kind of actions. The advantage of using precast concrete walls for protecting steel stud constructions is investigated in [6].

In general, the precast concrete wall façade should be able to protect the inside of the building from different threats such as vehicle impacts and ballistic attacks. Moreover, the concrete cladding panels can be integrated with other materials. The building life-cycle is also enhanced as a consequence of the precast concrete panel resistance to environmental attacks like acid rain and chlorine ion. In [7] the behavior of precast concrete panels with an insulation layer that improves the thermic qualities of the panel is investigated, focusing on the shear ties connecting the two concrete layers confining the insulation layer.

The panel and its surface are durable over time, and do not require expensive maintenance. In fact, this kind of cladding system is economically and ecologically sustainable, having all the advantages of precast structures.

Considering the above, this study focuses on the probabilistic approach for blast resistance assessment, and investigates the failure probability of a precast concrete wall subjected to blast loads (in particular far-field surface-blast loads). The wall under investigation is a nonbearing precast concrete panel used as exterior cladding wall for buildings. Typically the length and the width of these walls are subject to specific architecture requirements while their thickness is approximately $15 \mathrm{~cm}$. The steel reinforcements are generally placed in the 
middle of the cross section. From the blast design perspective, these walls should protect people and equipment from external bomb attacks.

The non-linear dynamic analyses are carried out by the well-established method of the equivalent non-linear single degree of freedom (SDOF) system, so the precast concrete wall is made equivalent to a non-linear SDOF. Both the fragility curves and the failure probability of the cladding wall are computed using Monte Carlo simulations.

Since the aim of this paper is to apply a probabilistic approach to the blast design, the fragility curves for a precast concrete cladding panel are computed for each component damage level defined in a Performance-Based Design prospective. Then the fragility curves are used to estimate the failure probability of the cladding panel subjected to a blast load scenario (vehicle bomb). Moreover the failure probability of the cladding panel subjected to the same scenario is estimated by a Monte Carlo simulation without using the fragilities curves.

The rest of this paper is organized as follows: Sections 2 and 3 provide respectively the details of the blast load and of the cladding model. Section 4 focuses on response parameters of the cladding under blast. Section 5 provides some insight on the implementation of fragility curves. Section 6 reports the results. Finally, some brief conclusions and suggestions for further developments are reported in Section 7.

\section{BLAST LOAD MODEL}

Blast engineering design is characterized by the presence of many uncertainties, which can be divided into three groups:

- load uncertainties: explosive weight, stand-off distance;

- structure uncertainties: stiffness, damping, material characteristic, etc.;

- interaction mechanism uncertainties: typically the reflected pressure, pressure duration, etc.

This classification of the uncertainties in three groups (load, structure, interaction mechanisms) is generally valid for many engineering fields. In [8] and [9] a framework for handling uncertainties implementing Monte Carlo simulation is presented and applied.

The side-on blast pressure $\mathrm{P}_{\mathrm{s} 0}[\mathrm{MPa}]$ can be estimated by the formula of Mills [10] (Eq. 1), while the side-on specific impulse $\mathrm{i}_{0}[\mathrm{~Pa} \mathrm{sec}]$ is estimated by the formula of Held [11] (Eq. 2).

$$
\begin{aligned}
\mathrm{P}_{\mathrm{S} 0}=1.772\left(\frac{\mathrm{W}}{\mathrm{R}^{3}}\right)- & 0.114\left(\frac{\mathrm{W}^{\frac{2}{3}}}{\mathrm{R}^{2}}\right)+0.108\left(\frac{\mathrm{W}^{\frac{1}{3}}}{\mathrm{R}}\right) \\
\mathrm{i}_{0} & =300\left(\frac{\mathrm{W}^{\frac{2}{3}}}{\mathrm{R}}\right)
\end{aligned}
$$

Where $\mathrm{W}$ is the explosive (charge) weight (usually in $\mathrm{kg}_{\mathrm{f}} \mathrm{TNT}$ ) and R is the stand-off distance $[\mathrm{m}]$.

Both Eq. 1 and Eq. 2 are valid for free-air explosions. In this study detonations occurring on a surface (surface explosions) are considered, therefore the energy of the detonation is confined by the ground surface. This phenomenon is taken into account by using the same equations for the free-air explosions but assuming that a given explosive charge weight (W) on a deformable ground produces the same load as a free-air explosion of a charge weight equal to $1.8 \mathrm{~W}$. 
The reflected pressure $\mathrm{P}_{\mathrm{r}}[\mathrm{MPa}]$ for a normal angle of incidence is computed using Eq. 3. [10]:

$$
\mathrm{P}_{\mathrm{r}}=2 \mathrm{P}_{\mathrm{s} 0}\left(\frac{7 \mathrm{P}_{\mathrm{atm}}+4 \mathrm{P}_{\mathrm{s} 0}}{7 \mathrm{P}_{\mathrm{atm}}+\mathrm{P}_{\mathrm{s} 0}}\right)
$$

Where $\mathrm{P}_{\mathrm{atm}}$ is the atmospheric pressure $(0.1 \mathrm{MPa})$.

Without loss of generality the negative pressure phase is neglected from the blast load time history [2], while the duration of the positive phase of the blast load is computed by assuming a triangular shape of the load function, given by:

$$
\mathrm{t}_{\mathrm{d}}=\frac{2 \mathrm{i}_{\mathrm{s} 0}}{\mathrm{P}_{\mathrm{s} 0}}
$$

The atmospheric pressure is obtained starting from the reflected pressure by means of the Friedlander pulse shape as shown in Eq. 5.

$$
P(t)=P_{r}\left(1-\frac{t}{t_{d}}\right) e^{\frac{-\beta t}{t_{d}}} \quad t_{a} \leq t \leq t_{d}
$$

Where $t_{a}$ is the arrival time of the blast load, here considered equal to zero, and $\beta$ is the decay coefficient. In this study a value of 1.8 for $\beta$ is assumed.

The cleaning effect is neglected in this study since the cladding wall is part of a building façade and no conditions are satisfied for the cleaning of the reflected shock wave [3].

In Figure 1 the blast load time histories computed with the described procedure for different values of the explosive weight $\mathrm{W}$ (in $\mathrm{kg}_{\mathrm{f}}$ ) and the stand-off distance $\mathrm{R}$ (in $\mathrm{m}$ ) are shown. A good agreement can be observed between the obtained curves and the curves obtained by SBEDS [12].

The blast load is considered uniformly distributed on the cladding wall, consistent with a scaled distance higher than approximately 1.2 to $2.0 \mathrm{~m} / \mathrm{kg}_{\mathrm{f}}^{1 / 3}$.

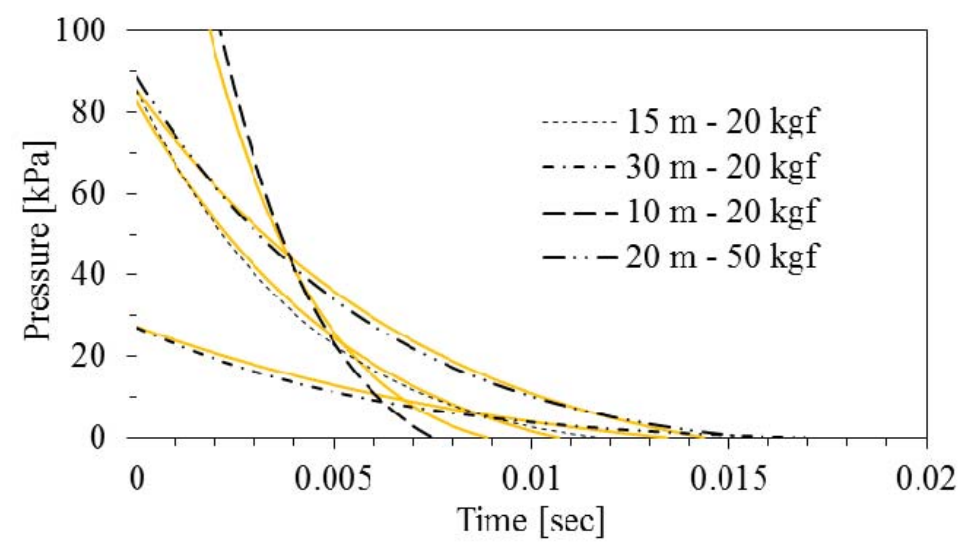

Figure 1: Blast loads (surface explosions) by the adopted model (dotted lines) and the SBEDS model (continuous line).

\section{CLADDING PANEL MODEL}

The cladding panel examined as case study is part of a frame structure building. A 3500 $\mathrm{mm}$ long and $1500 \mathrm{~mm}$ wide panel is used, having a cross section thickness of $150 \mathrm{~mm}$. The supports of the panel are placed on the external frame beams of the building. Length, width and cross section thickness are assumed as stochastic variables. Both the assumed mean values and Coefficients of Variations (COVs) are shown in Table 1. The longitudinal reinforce- 
ments consist in 10 rebar with a diameter of $10 \mathrm{~mm}$, and they are placed in the middle of the cross section. The strength mean value and coefficient of variation are shown in Table 1 as well. The panel under investigation does not have shear reinforcements and transversal reinforcements are not significant for the purpose of this study.

\subsection{Concrete model}

The concrete compressive strength $f_{c}$ is assumed as stochastic variable, while the Young's modulus of the concrete $E_{c}$ and the concrete density $\rho$ are expressed as functions of $f_{c}$.

The mean value of $f_{c}$ is $28 \mathrm{MPa}(4060 \mathrm{psi})$, with a COV of 0.18 as adopted in [13] for a lognormal probability density function (see Table 1 ).

The concrete Young's modulus is computed by Eq. 6 [14] and the concrete density is computed by Eq. 7 [15]. Both $E_{c}$ and $f_{c}$ are expressed in MPa while $\rho$ is expressed in $\mathrm{kg} / \mathrm{m}^{3}$.

$$
\begin{aligned}
& E c=22000\left(\frac{f_{c}}{10}\right)^{0.3} \\
& \rho=\left(\frac{E_{c}}{0.043\left(f_{c}^{0.5}\right)}\right)^{\frac{1}{1.5}}
\end{aligned}
$$

The compressive strength enhancement of the concrete due to the strain velocity is considered in this study. This strength enhancement is taken into account by means of the Dynamic Increasing Factor (DIF), a multiplicative coefficient of the concrete compressive resistance. Furthermore, since for ductile flexural response the compressive strength enhancement of the concrete varies slightly on the range of the strain velocity developed in the ductile flexural response, the DIF can be assumed constant and equal to 1.19 times the static compressive strength. This hypothesis is in accordance with the compressive strength enhancement proposed in [12], and is also convenient for avoiding cyclic iterations in the algorithm of the SDOF equation solver. However, cyclic iterations are necessary for computing the strength enhancement on the reinforcements, which is more crucial for ductile flexural response than the compressive strength enhancement on the concrete.

\subsection{Reinforcing steel model}

Concerning the reinforcing steel, the characteristic yielding strength is $450 \mathrm{MPa}(65250$ psi). For estimating the mean value of the yielding strength, an average strength factor equal to 1.1 is adopted as indicated in [12]. However experimental tests should be performed to validate this indication. The COV is of 0.12 as proposed in [13] for a lognormal probability density function (see Table 1). The Young's modulus is assumed as deterministic and equal to 210 GPA (30450 ksi).

The steel strength enhancement due to the strain velocity is taken into account by the Cowper and Symonds model. Thus, the DIF is provided by Eq. 8:

$$
\mathrm{DIF}=1+\left(\frac{\mathrm{d} \epsilon / \mathrm{dt}}{\mathrm{C}}\right)^{\frac{1}{\mathrm{p}}}
$$

Where $\mathrm{d} \varepsilon / \mathrm{dt}$ is the strain velocity on the reinforcements, $\mathrm{C}$ is taken equal to $500 \mathrm{sec}^{-1}$ and $\mathrm{p}$ is taken equal to 6 .

Both $\mathrm{C}$ and $\mathrm{p}$ are estimated by fitting the strength enhancement versus the strain velocity in [15]. Eq. 8 is graphically reproduced in Figure 2. By solving the SDOF equation of motion, the DIF is iteratively updated until a convergence threshold is reached. 


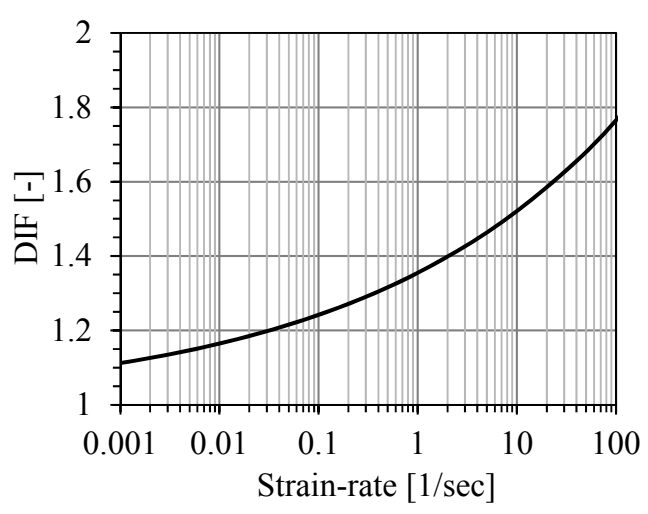

Figure 2: Reinforcing steel strength enhancement for different strain velocities.

The strain velocity of the steel reinforcements $(\mathrm{d} \varepsilon / \mathrm{dt})$ in Eq. 8 is calculated approximately by Eq. 9 .

$$
\frac{\mathrm{d} \varepsilon}{\mathrm{dt}}=\frac{\mathrm{dR}}{\mathrm{dt}} \frac{\mathrm{L}}{8}\left(\frac{\mathrm{d}}{2 \mathrm{E}_{\mathrm{c}} \mathrm{I}_{\mathrm{c}}}\right)
$$

Where $\mathrm{L}$ is the length of the cladding panel, $\mathrm{E}_{\mathrm{c}}$ is the Young's modulus of the concrete, $\mathrm{I}_{\mathrm{c}}$ is the moment of inertia of the cracked cross section, $d$ is the distance from the compressed external fiber of the cross-section to the centroid of the tension reinforcements, and $\mathrm{dR} / \mathrm{dt}$ is the rate of the resistance force developed by the panel $(\mathrm{R})$ when subjected to the demand load. Eq. 9 is valid for simply-simply supported elements, when the response is governed by the flexural behavior without shear failure.

\begin{tabular}{ccccc}
\hline Symbol & Description & Mean & COV & Distribution \\
\hline $\mathrm{f}_{\mathrm{c}}$ & Concrete strength & $28 \mathrm{MPa}$ & 0.18 & Lognormal \\
$\mathrm{f}_{\mathrm{y}}$ & Steel strength & $495 \mathrm{MPa}$ & 0.12 & Lognormal \\
$\mathrm{L}$ & Panel length & $3500 \mathrm{~mm}$ & 0.001 & Lognormal \\
$\mathrm{H}$ & Panel height & $150 \mathrm{~mm}$ & 0.001 & Lognormal \\
$\mathrm{b}$ & Panel width & $1500 \mathrm{~mm}$ & 0.001 & Lognormal \\
$\mathrm{c}$ & Panel cover & $75 \mathrm{~mm}$ & 0.01 & Lognormal \\
\hline $\mathrm{W}$ & Explosive weight & $227 \mathrm{~kg}$ & 0.3 & Lognormal \\
$\mathrm{R}$ & Stand-off distance & $15 \mathrm{~m} 20 \mathrm{~m} \mathrm{25} \mathrm{m}$ & 0.05 & Lognormal \\
\hline
\end{tabular}

Table 1: Input data.

\section{COMPONENT DAMAGE LEVELS}

For structural components subjected to blast loads, generally two response parameters are of interest: the support rotation angle $(\theta)$ and the ductility ratio $(\mu)$. These parameters are defined in Eq. 10 and Eq. 11:

$$
\begin{gathered}
\theta=\operatorname{arctg}\left(\frac{2 \delta_{\max }}{\mathrm{L}}\right) \\
\mu=\frac{\delta_{\max }}{\delta_{e}}
\end{gathered}
$$

Where $\delta_{\max }$ is the maximum deflection, $\mathrm{L}$ is the panel length, and $\delta_{\mathrm{e}}$ is the equivalent yield deflection of the resistance function.

A structural component subjected to a blast load is generally expected to yield, and it is impractical to design a member to remain in elastic range. While other significant response 
parameters can be defined, this study focuses on the response parameters usually adopted for antiterrorism design [12].

In a performance-based blast design prospective, five Component Damage Levels (CDLs) are usually considered: Blowout (BO), Hazardous Failure (HF), Heavy Damage (HV), Moderate Damage (MD), and Superficial Damage (SD). Following [12] the above mentioned levels are defined as follows:

- Blowout (BO): the component is overwhelmed by the blast load causing debris with significant velocities.

- Hazardous Failure (HF): the component has failed, and debris velocities range from insignificant to very significant.

- Heavy Damage (HD): the component has not failed, but it has significant permanent deflections causing it to be un-repairable.

- Moderate Damage (MD): the component has some permanent deflection. It is generally repairable, if necessary, although replacement may be more economical and aesthetic.

- Superficial Damage (SD): the component has no visible permanent damage.

The thresholds corresponding to these CDLs are defined in terms of the response parameters $\theta$ and $\mu$. For a concrete cladding wall without shear reinforcing and by neglecting tension membrane effects, the CDL thresholds are reported in Table 2. In the following the Fragility Curves (FCs) are computed for each component damage level.

\begin{tabular}{ccc}
\hline Component damage levels & $\theta[$ degree & $\mu[-]$ \\
\hline Blowout & $>10^{\circ}$ & none \\
Hazardous Failure & $\leq 10^{\circ}$ & none \\
Heavy Damage & $\leq 5^{\circ}$ & none \\
Moderate Damage & $\leq 2^{\circ}$ & none \\
Superficial Damage & none & 1 \\
\hline
\end{tabular}

Table 2: Component damage levels, and the associated thresholds in terms of response parameters.

\section{FRAGILITY CURVES}

The blast load on the panel depends on both the peak pressure and the impulse. The pressure depends directly on the scaled distance (defined as the stand-off distance divided by the cube root of the explosive weight). Nevertheless, the impulse density depends on both the scaled distance and the explosive weight (Eq. 1 and Eq. 2). Consequently, two detonations with the same scaled distance can have different impulse densities, depending on the amount of explosive. Thus, the two explosions have the same peak pressure but different duration.

Summarizing, the blast load depends on the scaled distance and the explosive weight. Therefore the choice of the intensity measure for computing the failure probability using fragility curves (FCs) is a crucial issue. In this study, the scaled distance is taken as intensity measure.

The FCs are consequently plotted in function of the scaled distance and the stand-off distance. This is for taking into account the dependence of the blast demand, and consequently the structural response by both the scaled distance and the amount of explosive.

FCs are developed for each of the CDL (see Figure 3). With reference to the same figure, "i" indicates the $i$-th point of the FC, " $j$ " is the $j$-th CDL, and " $k$ " is the $k$-th FC of the CDL related to the stand-off distance for which the $\mathrm{k}$-th $\mathrm{FC}$ is computed. "N" is the maximum val- 
ue for " $\mathrm{i}$ " and therefore the total number of point forming the FC. "M" is the maximum value for " $\mathrm{j}$ " and therefore the total number of the CDLs. Finally " $\mathrm{L}$ " is the maximum value of " $\mathrm{k}$ " therefore the total number of the stand-off distances for which the $\mathrm{j}$-th $\mathrm{FC}$ is computed.

The j-th FC for the k-th stand-off distance (FC CDL $(j, k)$ ) is built selecting the $j$-th CDL and the k-th stand-off distance and varying the explosive weight. The i-th point of the FC (FC $\operatorname{CDL}(\mathrm{i}, \mathrm{j}, \mathrm{k}))$ is therefore computed by considering the blast load at the $\mathrm{k}$-th stand-off distance and by considering a value of the explosive weight. The minimum and maximum amount of explosive weight should be enough for making the value of the FC CDL (j, k) from 1 to 0.

The complete (cyclic) procedure of Figure 3 is hereby described. First a k-th stand-off distance is selected, then the " $\mathrm{j}$ " CDL is selected, and consequently the $\mathrm{i}$-th point of the FC CDL $(j, k)$ is computed until tracking the complete FC CDL $(j, k)$. The FC CDL $(i, j, k)$ is obtained by a Monte Carlo simulation. After that a new $\mathrm{j}$-th CDL is considered with the same value of " $\mathrm{k}$ ". When $\mathrm{j}=\mathrm{M}$ a different stand-off distance is selected and the previous two described cycles are repeated until $\mathrm{k}=\mathrm{L}$.

As said, the failure probability of each CDL is estimated, but the Coefficient of Variance of such Failure Probability $\left(\mathrm{P}_{\mathrm{f}}\right)$ increases with the decrease of $\mathrm{P}_{\mathrm{f}}$, so the COV is not constant with the $\mathrm{P}_{\mathrm{f}}$ values. In order to obtain an acceptable COV it is necessary to increment the number of samples in the Monte Carlo analysis. In this work these samples decrease exponentially with decreasing $Z$, since for higher values of $Z$ the cladding wall has an inferior structural response than for lower $Z$ values. Thus, it is expected that the $\mathrm{P}_{\mathrm{f}}$ is lower for higher values of $\mathrm{Z}$.

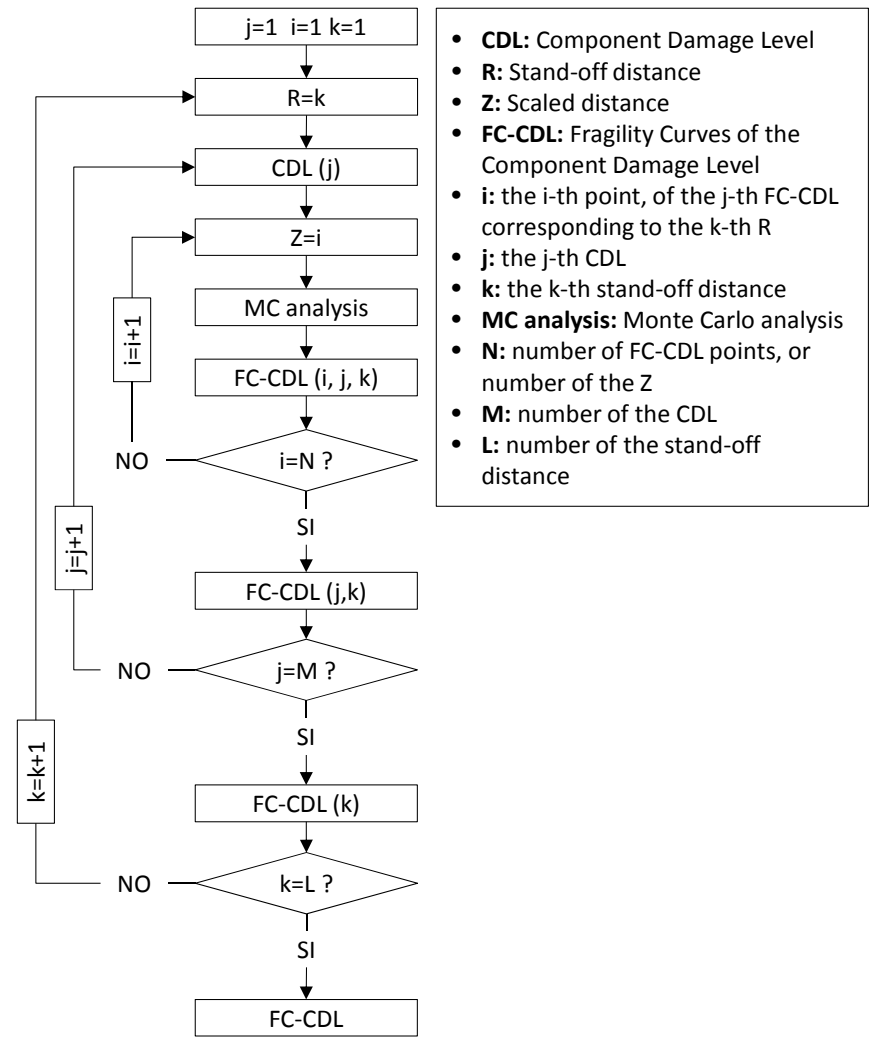

Figure 3: Fragility curve computation flowchart.

\section{NUMERICAL RESULTS}

This section focuses on the presentation of results on i) the fragility curves of the cladding panel case study, and, ii) the failure probability of such cladding panel estimated by both the fragility curves and the Monte Carlo simulation. 
In Figure 4 the computed fragility curves are plotted as a function of the scaled distance. For the specific panel case study, the fragility curves of the SD component damage level appear with a different slope rate compared to the other three component damage levels (HF, $\mathrm{HD}$, and MD). It should be noted that the SD component damage level is based on the ductility $(\mu)$ of the component while HF, HD, and MD component damage levels are based on the support rotation $(\theta)$. The SD component damage level for a concrete cladding panel prescribes the elastic response of the component, and for the case study panel it appears to be more sensitive to the considered uncertainties compared to the HF, HD, and MD damage levels. By varying the number of samples the maximum obtained COV for the lower failure probability (close to zero), is about 9\%. This value is considered acceptable for the specific case, and it is consistent with other studies on blast applications (see [4]). These fragility curves are the probabilistic representation of the mechanical properties of the concrete cladding panel and are useful for computing the failure probability of a set of blast scenarios for the different CDLs. If the stochastic characterization of the blast scenario is neglected, assuming for example the conventional performance demand, the fragility curves of Figure 4 can be used as a design tool. Selecting a blast scenario characterized by both the amount of explosive and the stand-off distance it is possible to establish the failure probability of the panel and check if this failure probability is lower than an acceptable failure probability. Different cladding panels can be certified using these fragility curves, something that facilitates the design process of the specific panel against blast loads. Thus, the fragility curves (Figure 4) can be considered as a design chart when the load is conventionally defined.
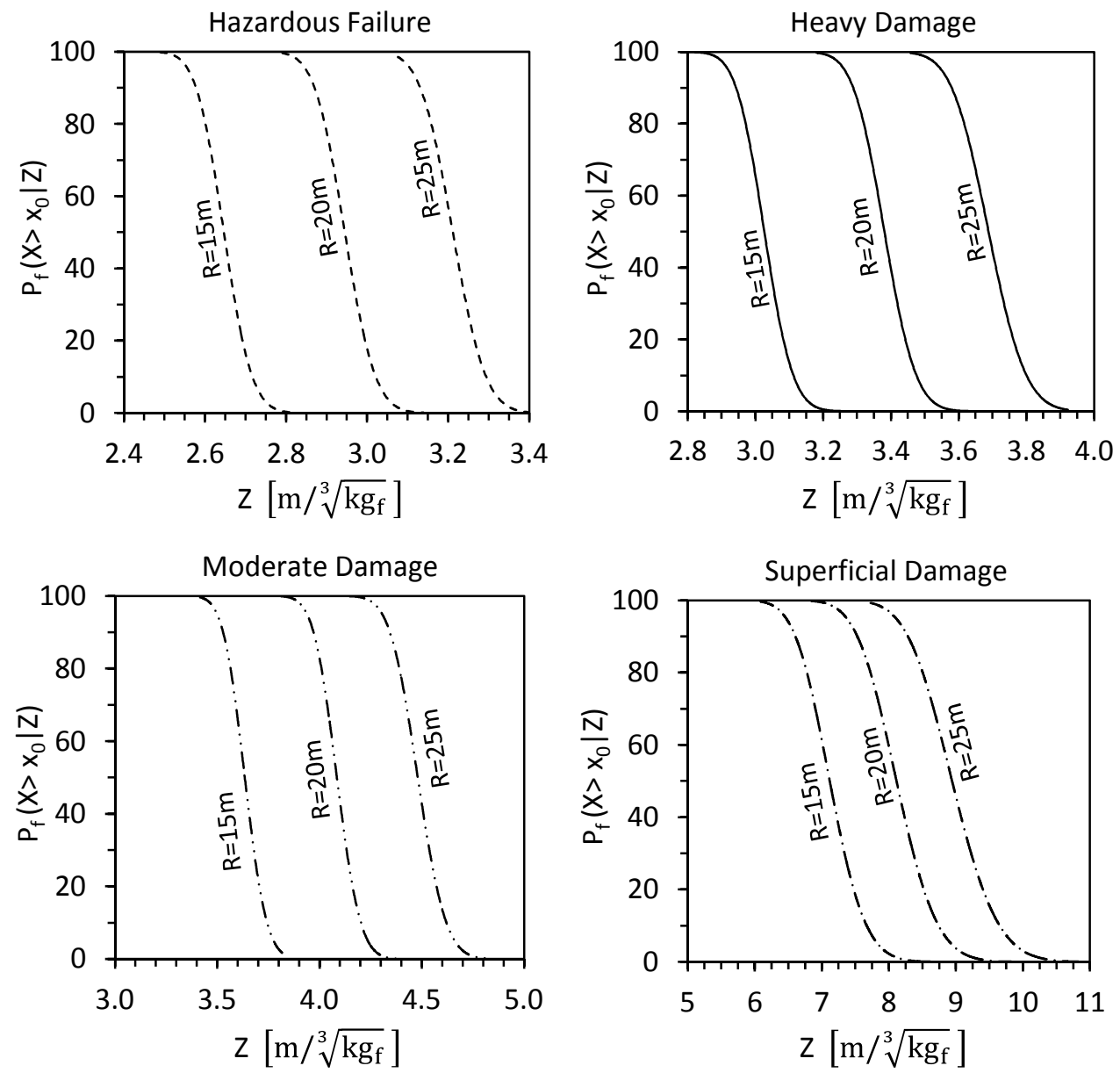

Figure 4: From top left clockwise, fragility curves for the HF, HD, SD, MD component damage levels. 
For computing the $\mathrm{P}_{\mathrm{f}}$ from the fragility curves it is necessary to characterize stochastically the blast scenario and integrate Eq. 12. In this study a vehicle bomb is considered. The amount of explosive in the vehicle depends among else on the security measures in place, and for each line of security a different mean value of the amount of explosive is expected. The mean value of the amount of explosive decrease with decreasing stand-off distance from the target, since the lines of security system reduce progressively the severity of the possible attacks. In the specific case a vehicle bomb (with about 27 to $454 \mathrm{~kg}_{\mathrm{f}}$ of TNT or equivalent) is considered. The mean amount of TNT or equivalent in the vehicle is $227 \mathrm{~kg}_{\mathrm{f}}$ with a coefficient of variation equal to 0.3 (see Table 1). This estimation is in line with the data provided in [16]. The stand-off distance is placed at $20 \mathrm{~m}$ and its coefficient of variation is 0.05 , considering that the vehicle could impact and overpass the fence barrier but without being able to move further. Eq. 12 computes the conditional failure probability of the CDL with respect to the event realization $\left(\mathrm{P}\left(\mathrm{X}>\mathrm{x}_{0}\right)\right)$. $\mathrm{X}$ is the union of the two response parameters characterizing the component damage level (see Table 2). The probability density of the scaled distance $(\mathrm{p}(\mathrm{Z}))$ is computed by extracting both the explosive weight and the stand-off distance with a lognormal distribution. The fragility curve $\left(\mathrm{P}\left(\mathrm{X}>\mathrm{x}_{0} \mid \mathrm{Z}\right)\right)$ for Eq. 12 is the one corresponding to the mean value of the stand-off distance proper of the blast scenario (Table 1).

$$
\mathrm{P}\left(\mathrm{X}>\mathrm{x}_{0}\right)=\int_{-\infty}^{+\infty} \mathrm{P}\left(\mathrm{X}>\mathrm{x}_{0} \mid \mathrm{Z}\right) \mathrm{p}(\mathrm{Z}) \mathrm{dz} \cong \sum_{\mathrm{i}=0}^{\infty} \mathrm{P}\left(\mathrm{X}>\mathrm{x}_{0} \mid \mathrm{Z}\right)_{\mathrm{i}} \mathrm{p}(\mathrm{Z})_{\mathrm{i}} \Delta \mathrm{Z}_{\mathrm{i}}
$$

$\mathrm{P}\left(\mathrm{X}>\mathrm{x}_{0}\right)$ is estimated for three scenarios. The amount of explosive is the same but the mean value of the stand-off distance varies (respectively 15, 20 and 25 meters). As a consequence, the considered fragility curve for each scenario is different. As previously mentioned the fragility curve adopted for solving Eq. 12 is the one for a stand-off distance equal to mean value of the stand-off distance of the blast scenario. In Table 3 the obtained results are shown. The first column reports the CDLs, while the second and third report the conditional failure probability (to the event realize) for each blast scenario obtained respectively by Eq. 12 and by the Monte Carlo analysis.

\begin{tabular}{|c|c|c|c|}
\hline \multirow{2}{*}{ CDL } & \multicolumn{3}{|c|}{$\begin{array}{c}\text { Mean } \mathrm{W}=227 \mathrm{~kg}_{\mathrm{f}} \mathrm{COV}=0.3 \text { lognormal distribution } \\
\mathrm{R}, \mathrm{COV}=0.05 \text { lognormal distribution }\end{array}$} \\
\hline & FC analysis & MC analysis & difference $\Delta \%$ \\
\hline \multicolumn{4}{|c|}{ Mean $\mathrm{R}=20 \mathrm{~m}$} \\
\hline SD & $100.0 \%$ & $100.0 \%$ & $0.0 \%$ \\
\hline MD & $96.6 \%$ & $97.5 \%$ & $0.9 \%$ \\
\hline HD & $55.7 \%$ & $55.5 \%$ & $0.3 \%$ \\
\hline $\mathrm{HF}$ & $13.6 \%$ & $12.1 \%$ & $11.0 \%$ \\
\hline \multicolumn{4}{|c|}{ Mean $\mathrm{R}=25 \mathrm{~m}$} \\
\hline SD & $100.0 \%$ & $100.0 \%$ & $0.0 \%$ \\
\hline MD & $74.6 \%$ & $77.3 \%$ & $3.5 \%$ \\
\hline HD & $14.2 \%$ & $12.6 \%$ & $11.2 \%$ \\
\hline $\mathrm{HF}$ & $1.02 \%$ & $1.02 \%$ & $0.0 \%$ \\
\hline \multicolumn{4}{|c|}{ Mean $\mathrm{R}=15 \mathrm{~m}$} \\
\hline SD & $100.0 \%$ & $100.0 \%$ & $0.0 \%$ \\
\hline MD & $97.9 \%$ & $99.9 \%$ & $2.0 \%$ \\
\hline HD & $93.6 \%$ & $96.9 \%$ & $3.4 \%$ \\
\hline $\mathrm{HF}$ & $67.8 \%$ & $72.6 \%$ & $6.6 \%$ \\
\hline
\end{tabular}

Table 3: Overview of the $P_{f}$. 
The first consideration is that the amount of explosives in the vehicle has a dominant role on the failure probability. The standard deviation of the explosive weight is 0.3 times the mean value and this level of dispersion is predominant on computing the failure probability for a CDL. If both the explosive weight mean value and the stand-off distance result in a scaled distance on the range of the FC, this leads to a $\mathrm{P}_{\mathrm{f}}$ close to $50 \%$ since the explosive weight has a higher standard deviation than the other parameters.

From these results the maximum percentage difference between the failure probability computed by the fragility curves and the Monte Carlo simulation is $11 \%$. Further studies are necessary to confirm whether this difference is acceptable or not. However it is also necessary to consider that the amount of explosives in the vehicle has an elevated dispersion, something that amplifies this difference due to the dependence of the impulse density by both the scaled distance and the explosive weight. Thus, being the impulse density proportional to both the explosive weight and the scaled distance, the difference between the failure probability computed by the fragility analysis method and by the MC simulation method increases with the increase of the difference between the stand-off distance with which the fragility curve is computed and the stand-off distance of the blast scenario estimated by $\mathrm{Z} \sqrt[3]{\mathrm{W}}$. In general such difference can be estimated considering the scaled distance and the explosive weight as the mean values of the blast scenario or by the single $\mathrm{Z}$ and $\mathrm{W}$ values at each "i" in Eq. 12. A future study could focus on the quantification of this difference and on developing a corrective method that leads to using a fragility curve independently from its stand-off which it is computed.

\section{CONCLUSIONS AND FURTHER DEVELOPMENTS}

In this paper a probabilistic approach for designing and assessing a cladding panel subjected to a blast load has been proposed. The blast load model has been adopted on the basis of empirical laws, and the geometry and mechanical properties of the panel are assumed as stochastic. A mechanical model equivalent to a SDOF has been adopted for describing the motion of the panel under an impulsive load. The fragility curves for each component damage levels are hence computed for a cladding panel subjected to blast loads, and these fragility curves are used for computing the failure probability, for each component damage level, of the panel subjected to three different blast scenarios. Furthermore, the failure probabilities are estimated using Monte Carlo simulations.

This study highlights the feasibility and effectiveness of a probabilistic approach for the design and assessment of protective structures, having as a principal limitation that the computed failure probability of the component damage level is conditional to the event realization. Computing the unconditional failure probability of the component damage level is tricky since the probability density function of the event in time is unknown. Even if the failure probability was known, it would be difficult to implement in the design phase, since a terroristic vehicle bomb attack is a low probability event. The solution presented in this paper is posed as a basis for the decision making based on the conditional failure probability of the event. However the failure probability of the component damage level has to be fixed on the basis of some criteria.

Future studies could take into account the deterioration of the materials of the different components in the fragility curves, during the entire life cycle - see for example [17]. Moreover, soft-computing methods could be implemented for the more efficient treatment of the uncertainties [18]. 


\section{ACKNOWLEDGEMENTS}

The author gratefully acknowledges the scientific contribution of Dr. Francesco Petrini, Dr. Konstantinos Gkoumas and Prof. Franco Bontempi of the Sapienza University of Rome.

\section{REFERENCES}

[1] L. Giuliani, Structural safety in case of extreme actions. International Journal Lifecycle Performance Engineering, 1(1), 22-40, 2012.

[2] UFC 3-340-02, Structures to resist the effects of accidental explosions. United States of America: Department of Defense, 2008.

[3] D.B. Chang, C.S. Young, Probabilistic estimates of vulnerability to explosive overpressures and impulses. Journal of Physical Security, 4(2), 10-29, 2010.

[4] M.G. Stewart, M.D. Netherton, Security risks and probabilistic risk assessment of glazing subject to explosive blast loading. Reliability Engineering and System Safety, 93(4), 627-638, 2008

[5] J.S. Davidson, J.W. Fisher, M.I. Hammons, J.R. Porter, J. Dinan, Failure mechanisms of polymer-reinforced concrete masonry walls subjected to blast. Structural Engineering, 131(8), 1194-1205, 2005.

[6] C.J. Naito, R. Dinan, B. Bewick, Use of precast concrete walls for blast protection of steel stud construction. Journal of Performance of Constructed Facilities, 25(5), 454463, 2011.

[7] C.J. Naito, J. Hoemann, M. Beacraft, B. Bewick, Performance and characterization of shear ties for use in insulated precast concrete sandwich wall panels. Journal of Structural Engineering, 138(1), 1-11, 2012.

[8] F. Petrini, H. Li, F. Bontempi, Basis of design and numerical modeling of offshore wind turbines. Structural Engineering and Mechanics, 36(5), 599-624, 2010.

[9] F. Petrini, F. Bontempi, Estimation of fatigue life for long span suspension bridge hangers under wind action and train transit. Structure and Infrastructure Engineering, 7(7-8), 491-507, 2011.

[10] C.A. Mills, The design of concrete structures to resist explosions and weapon effects. $1^{\text {st }}$ International Conference for Hazard Protection, Edinburgh, September 27-30, 1987.

[11] M. Held, Blast waves in free air. Propellants, Explosives, Pyrotechnics, 8(1), 1-7, 1983.

[12] TR-06-01 - US Army Corps of Engineers. Methodology Manual for the Single-Degreeof-Freedom Blast Effects Design Spreadsheets (SBEDS). 2008.

[13] M.P. Enright, D.M. Frangopol, Probabilistic analysis of resistance degradation of reinforced concrete bridge beams under corrosion. Engineering Structures, 20(11), 960-971, 1998.

[14] UNI EN 1992 - Eurocode 2 - Design of concrete structures - Part 1-1: General rules and rules for buildings. European Committee for Standardization, 2005.

[15] ACI 318, Building Code Requirements for Reinforced Concrete. American Concrete Institute, 1995. 
[16] FEMA 452 The Federal Emergency Management Agency (FEMA). Risk assessment: A How-To Guide to Mitigate Potential Terrorist Attacks Against Buildings, Providing protection to people and buildings, 2005.

[17] L. Sgambi, P.G. Malerba, G. Gotti, D. Ielmini, The influence of degradation phenomena on collapse modes in prestressed concrete beams. International Journal of Lifecycle Performance Engineering, 1(1), 41-63, 2012.

[18] L. Sgambi, K. Gkoumas, F. Bontempi, Genetic algorithms for the dependability assurance in the design of a long-span suspension bridge, Computer-Aided Civil and Infrastructure Engineering, 27(9), 655-675, 2012. 